\title{
LEG MECHANISM MOTION AND STRUCTURAL ChaRACTERISTICS
}

\author{
Comănescu Adriana, Comănescu Dinu, Dugăeșescu Ileana \\ University POLITEHNICA of Bucharest, Department of Mechanisms and Robots Theory, Splaiul Independentei no.313, \\ Bucharest, 060042, Romania
}

\begin{abstract}
The paper deals with a method for the structural, kinematic and dynamic analysis of bi-mobile and multi-looped planar mechanisms. In order to illustrate the theoretical concepts a leg mechanism selected from the patent literature is brought into attention. By using the theoretical bases and terminology of the mechanism theory and the inverse and direct modelling the motion characteristics are determined. For any trajectory of the effector extreme point it is possible to establish the main kinematic characteristics of any link and the dynamic characteristics of the active pairs in the same conditions. The new mechanical solutions in robotics for arm robots or legs for mobile robots require mechanisms with two or three degrees of mobility their structures including active kinematic pairs non-connected at the basis. A distinguished part of the paper includes new structural solutions based on the same leg linkage, which give possible new patents.

The paper is relevant from two points of view. The first aspect is the method of kinematic and dynamic analysis of bimobile mechanisms. The second one is the method of structural synthesis of similar mechanisms, which allows creating new original systems.
\end{abstract}

Keywords: Leg mechanism; robot arm; bi-mobile mechanism; inverse structural model; direct structural model; structural solution; passive modular group; active modular group
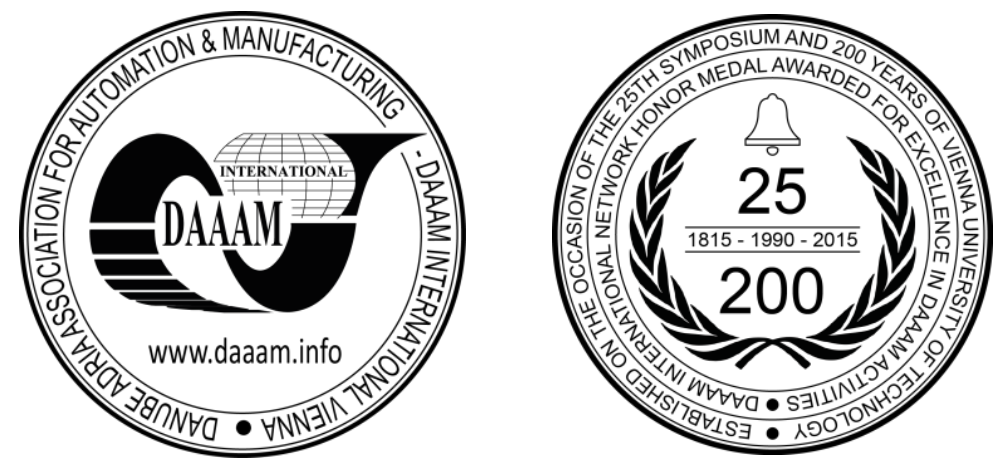

This Publication has to be referred as: Comanescu, A[driana]; Comanescu, D[inu] \& Dugaesescu, I[leana] (2016). Leg Mechanism Motion and Structural Characteristics, Proceedings of the 26th DAAAM International Symposium, pp.0173-0181, B. Katalinic (Ed.), Published by DAAAM International, ISBN 978-3-902734-07-5, ISSN 1726-9679, Vienna, Austria DOI:10.2507/26th.daaam.proceedings.024 


\section{Introduction}

The bi-mobile mechanisms with closed loops are usually used in robotics for leg mechanisms and robot arms $[1,2,3,4,5]$. Their main advantage is given by the fact that an extreme point of a link which motion depends on both independent parameters may describe any curve in its motion plane.

In its first part the paper includes the kinematic characteristics of the leg mechanism (Fig. 1) selected from the literature $[1,2,3,5]$. All these are obtained by means of its inverse model when it is necessary to describe a given trajectory for the extreme point of the output link. The dynamic characteristics of the torque components for each pair including both active pairs may be also determined by means of the leg mechanism direct model.

a

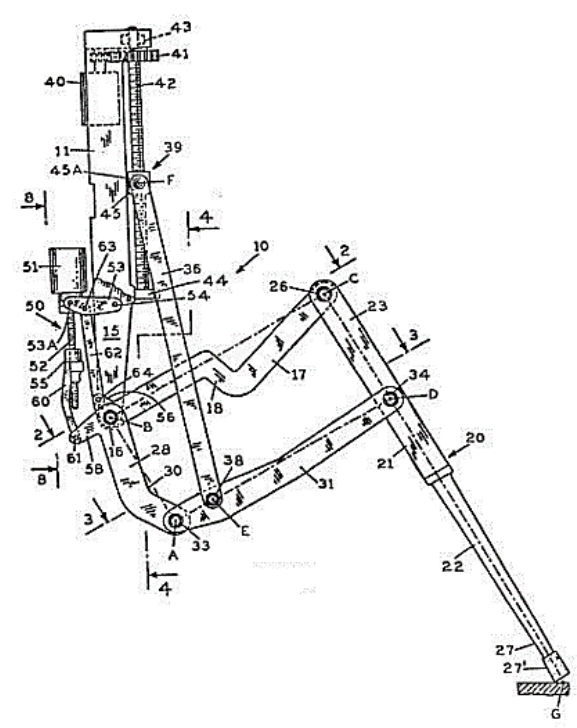

b

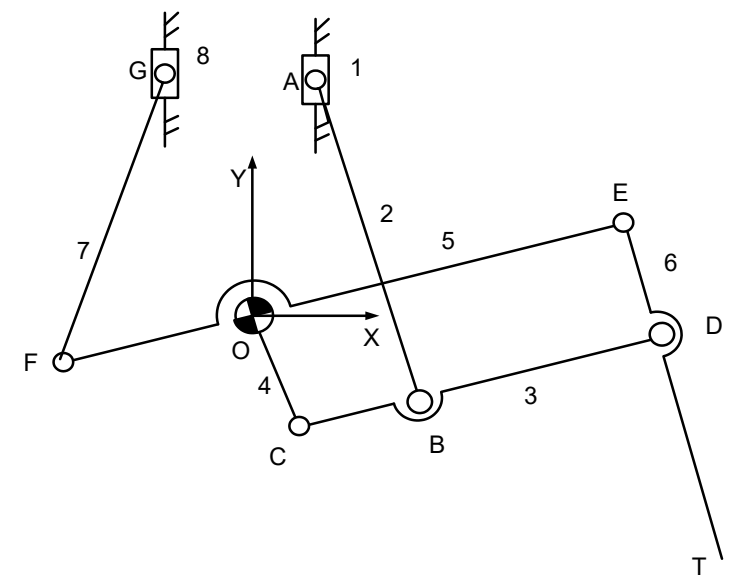

Fig. 1. (a) The leg mechanism patent;

b) The 2T-9R kinematic model for the leg mechanism patent

(In the last part of the paper the structural characteristics of the leg mechanism chain are analyzed and there are put into evidence all structural solutions which may generate new patents.

\section{Main structural characteristics}

The leg mechanism (Fig. 1) has 8 mobile links and 11 lower pairs and consequently its degree of mobility is two. Such mechanism may describe with an extreme point of the output link any trajectory. The direct model (Fig. 2a) puts into evidence the dependence of the $\mathrm{T}$ point coordinates to the parameters of the active pairs A and G, that is XT=XT(YA, YG) and YT=YT(YA, YG). This model includes two modular active groups and two AMG modular passive groups of the RRR dyad type and 6R triad type [5].

a

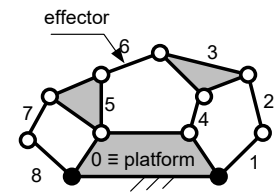

b

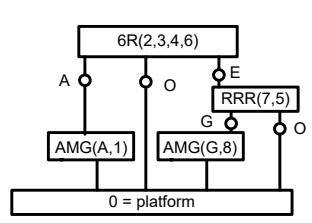

Fig. 2. (a) The leg mechanism patent;

(b) The connection of modular groups for the structural direct model

The inverse model may give the dependence of the active pair parameters in function of the extreme point $\mathrm{T}$ coordinates, that is $\mathrm{YA}=\mathrm{YA}(\mathrm{XT}, \mathrm{YT})$ and $\mathrm{YG}=\mathrm{YG}(\mathrm{XT}, \mathrm{YT})$. In this case when the coordinates of the $\mathrm{T}$ extreme point is imposed it is similarly to reduce the degree of mobility. The instantaneous degree of mobility $\mathbf{M}$ instantaneous becomes equal to zero. The structural inverse model (Fig. 3a) has four modular passive groups.

a

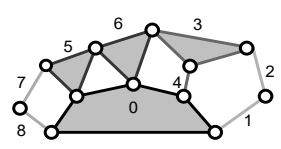

$\mathrm{b}$

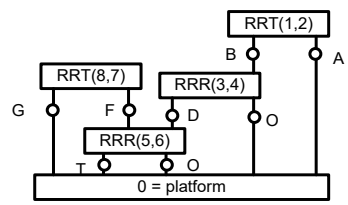

Fig. 3. (a) The structural inverse model;

(b) The connection of modular groups for the structural inverse model 
Having in view the bi-mobile and three loops kinematic chain (Fig. 4) from which the structural model is based (Fig. 2.a) one may put into evidence the basis and the effector, which must satisfy the following conditions:

- the effector must have a planar motion depending on two independent parameters;

- the effector cannot be adjacent to the basis;

- the basis and the effector cannot belong to the same four bars linkage, Watt linkage or Stephenson linkage (Fig. 5).

a

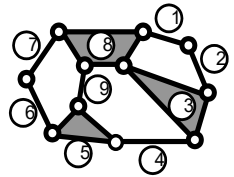

Fig. 4. The bi-mobile kinematic chain b
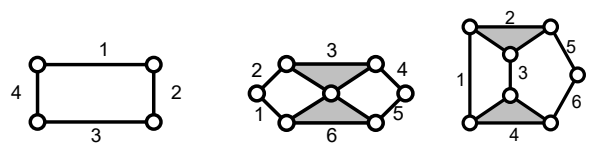

(Fig. 5. Linkages with one degree of mobility and one and two independent contours

The possible bases and effectors are given in the basis - effector matrix of the bi-mobile linkage which is a symmetrical one with the elements of the principal diagonal equal to zero [5], so that $\mathrm{A}[\mathrm{i}, \mathrm{j}]=\mathrm{A}[\mathrm{j}, \mathrm{i}]$ and $\mathrm{A}[\mathrm{i}, \mathrm{i}]=0$ where $\mathrm{i}$ is the basis and $\mathrm{j}$ is the effector. The inverse model of a bi-mobile linkage with 9 links and three loops may have the following passive modular groups (PMG) connections: $2+2+2+2,2+4+2,2+2+4,4+2+2,4+4,2+6$, $6+2$ or 8 elements $[5,6]$.

The mechanism patent is a solution which inverse model is given by $2+2+2+2$ passive modular groups (Fig. 3.a) when the $0 \equiv$ platform basis is the 8 link and the 6 effector is respectively the 4 link in Fig. 4 of the bi-mobile kinematic chain. A more detail structural analysis is presented in the last part of the paper.

\section{Motion characteristics given by the inverse model}

The bi-mobile mechanism (Fig. 1.) may describe any curve with its T extreme point of the effector. An example is that given in Fig. 6.

a

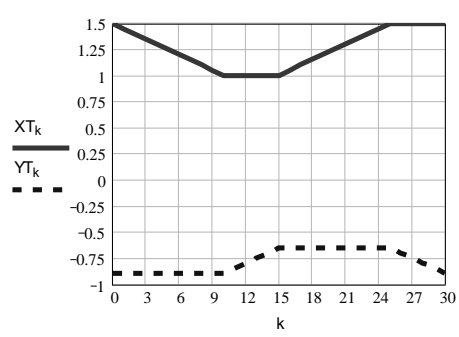

$\mathrm{b}$

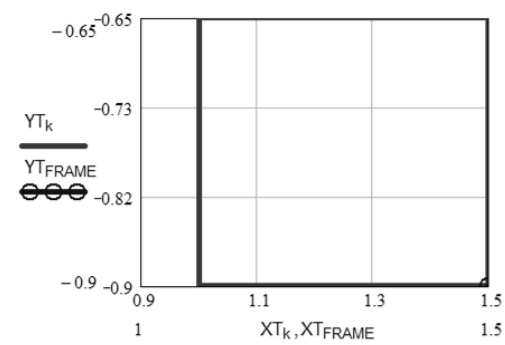

Fig. 6. (a) The $\mathrm{T}$ point coordinates variation; (b) The chosen curve for the $\mathrm{T}$ point

By using the inverse structural model (Fig. 3a.) the positional parameters of each link (Fig. 7) are determined by means of standard modules [5, 6] previously elaborated. The variation of the parameters corresponding to the chosen curve for the $\mathrm{T}$ extreme point of the output link is given in Fig. 8. The $\mathrm{s} 1_{\mathrm{k}}=\mathrm{YA}_{\mathrm{k}}$ (Fig. 8.c) and $\mathrm{s} 2_{\mathrm{k}}=\mathrm{YG}_{\mathrm{k}}($ Fig. 8.d) are the parameters of the active pairs A and G.

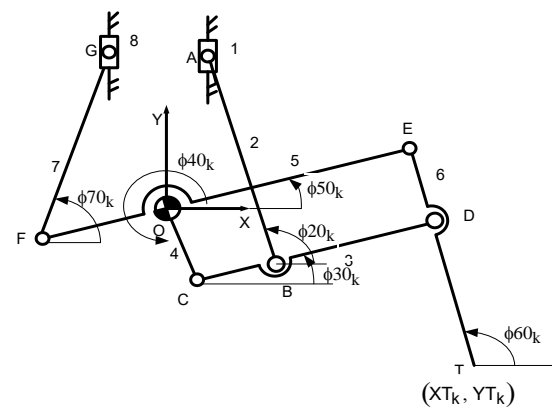

Fig. 7. The mechanism with its positional parameters for the inverse model 
a

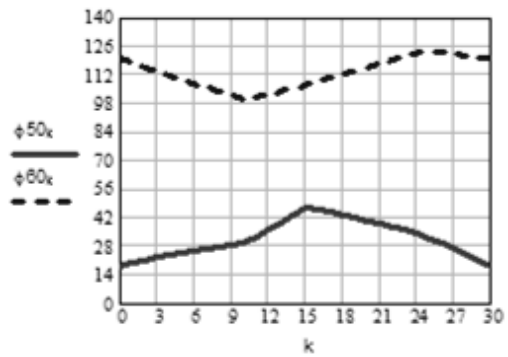

c

d
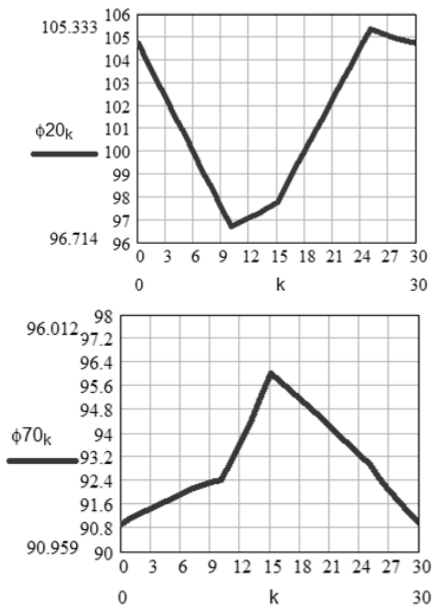
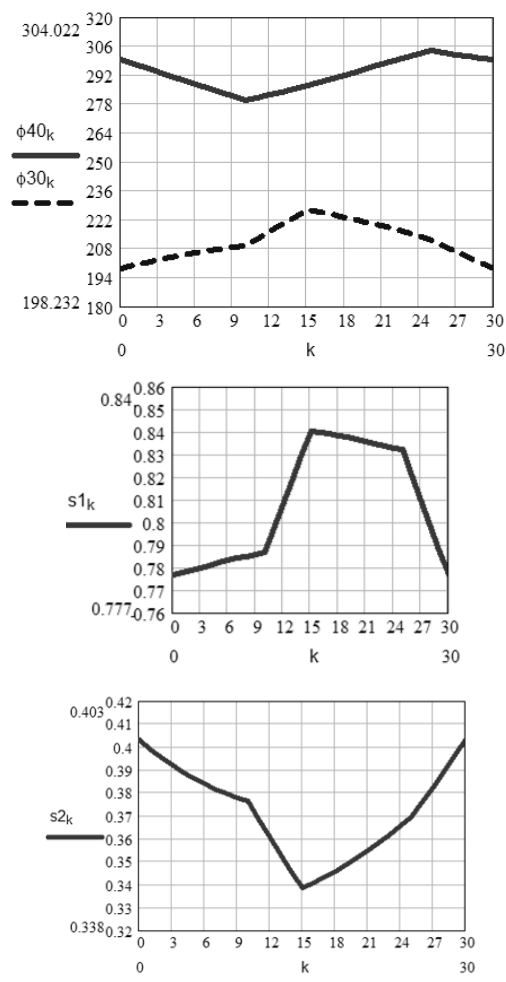

Fig.8. (a) the parameters of the RRR(6,7) passive group; (b) the parameters of the $R R R(3,4)$ passive group; (c) the parameters of the RRT $(1,2)$ passive group; (d) the parameters of the $\operatorname{RRT}(8,7)$ passive group

The trajectory of some characteristics points representing the lower pairs are given in Fig. 9. The Fig. 9.a and Fig. 9.b justify the calculus modules. In order to have the trajectory of the T extreme point (Fig. 6) it is necessary to apply the direct model given in Fig. 2 and to act simultaneously the active pairs A and G by the laws presented in Fig. 8 . $\mathrm{c}, \mathrm{d}$.

When one of them is blocked and only one is acted, the system has only one degree of mobility. Its modular group connections are given in Fig. 10.

a

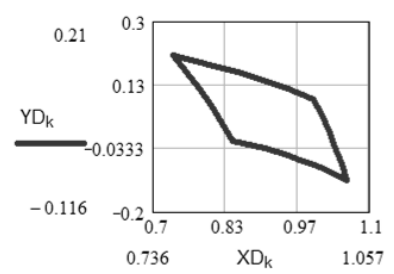

$\mathrm{c}$

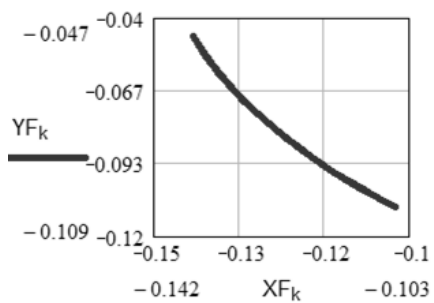

b

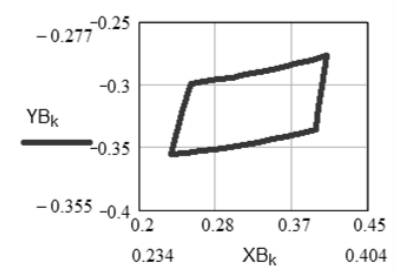

d

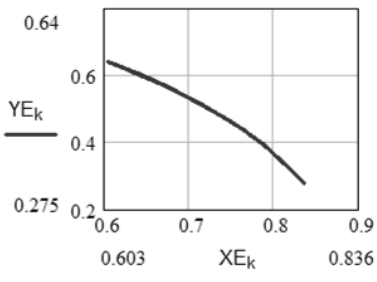

Fig. 9. (a) The trajectory of the D pair; (b) The trajectory of the B pair;

(c) The trajectory of the F pair; (d) The trajectory of the E pair

a

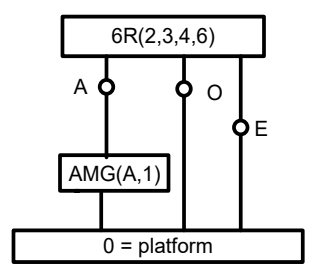

b

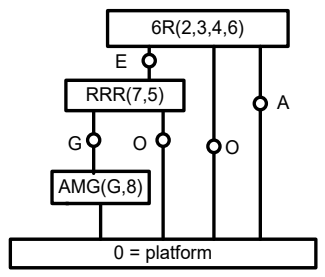

Fig. 10. (a) The model with the G pair blocked; (b) The model having the A pair blocked 
The parameters characteristics for the model given in Fig. 10 a are shown the Fig. 11. By applying the previously elaborated modules [5] one may analyze the behavior of the mechanism with only one degree of mobility. When the $\mathrm{G}$ active pair is blocked the links 5 and 7 remain fixed. The mechanism kinematic analysis implies $6 \mathrm{R}$ triad (Fig.10. b).

There are determined the characteristics in two cases, when the angle $\Phi 50$ has extreme positions. Meantime the active pair A may have a complete course between its extreme positions. For each extreme positions of the 8 link the link parameters are determined and their variations in function of the $\mathrm{YA}_{\mathrm{i}}=\mathrm{s} 1_{\mathrm{i}}$ parameter (Fig. 12) are comparatively presented in Fig.13 a, b. Someone may note the little variations of angular parameters for any links.

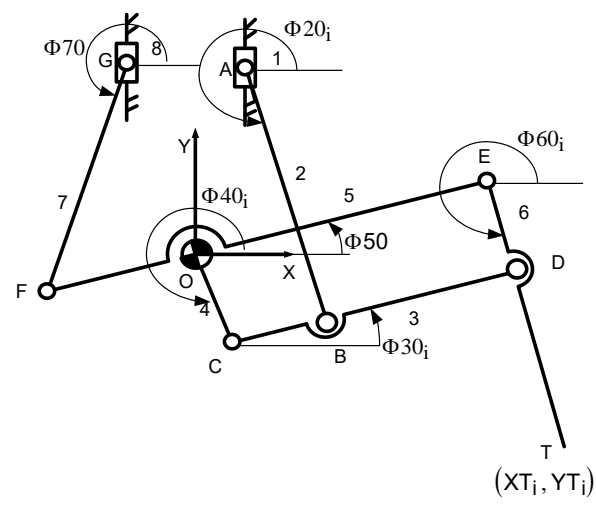

Fig. 11. The mono-mobile mechanism with the $\mathrm{G}$ active pair blocked
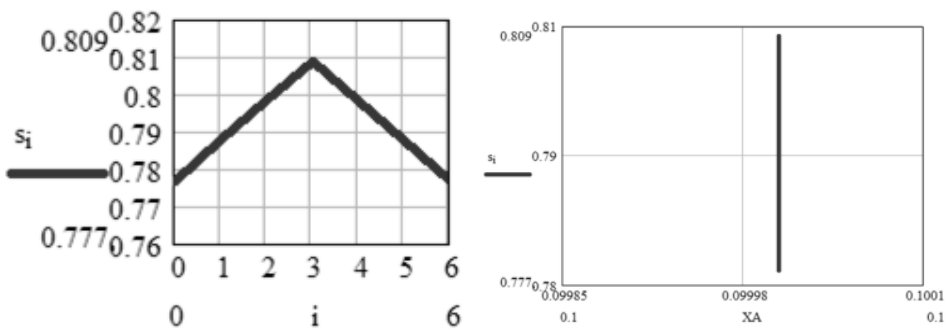

Fig. 12. The variation of the $\mathrm{YAi}=\mathrm{s}$ li parameter for the active pair $\mathrm{A}$

a

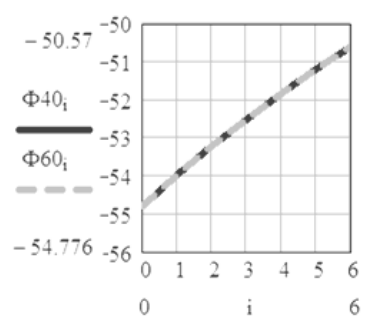

a

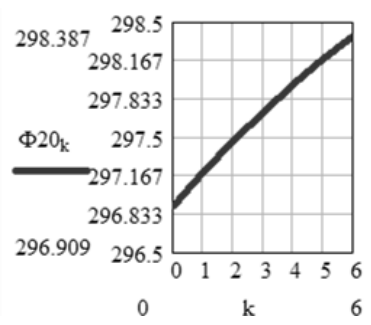

a

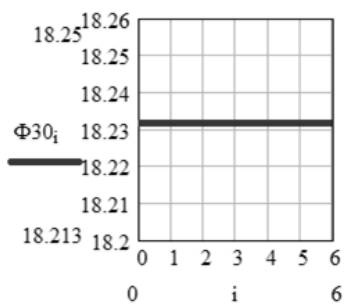

b

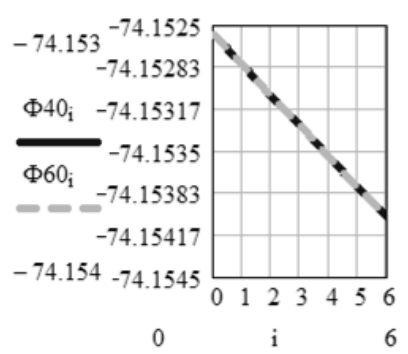

b

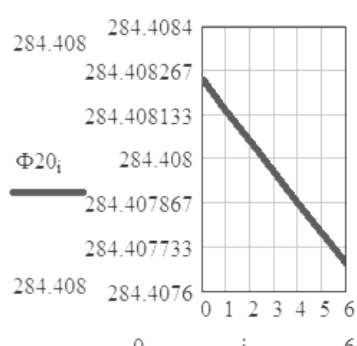

$\mathrm{b}$

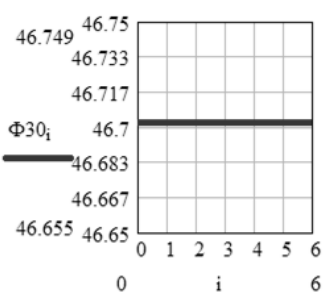


a

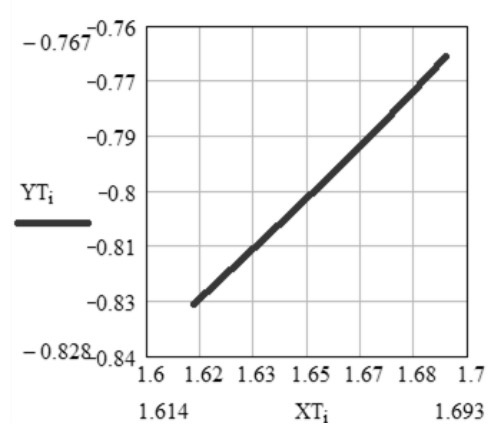

b

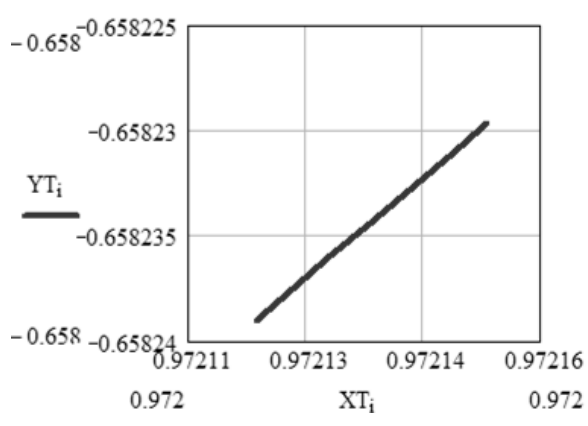

Fig. 13. The variation of parameters (a) for the $\Phi 50$ minimum angle; (b) for the $\Phi 50$ maximum angle

\section{The dynamic characteristics for the bi-mobile mechanism}

By means of the direct model (Fig. 2a) the reaction torque components of each pair may be determined. The final purpose is to establish the active force acted respectively on 1 and 8 links (Fig. 1) that is T01 and T08 during its functioning. In order to simplify the problem the $\mathrm{T}_{\mathrm{i}}$ mass centers of links are placed in $\mathrm{O} \equiv \mathrm{T}_{5} \equiv \mathrm{T}_{4} ; \mathrm{B} \equiv \mathrm{T}_{2} \equiv \mathrm{T}_{3} ; \quad E$ $\equiv \mathrm{T}_{6} ; \mathrm{F} \equiv \mathrm{T}_{7}$.In Fig. 14 there shown the dynamic models for the RRR dyad, the 6R triad and for the simplest active group with a prismatic pairs. In the $\mathrm{T}_{\mathrm{i}}$ mass centers of links there are placed the equivalent torque of external and inertia forces.

a

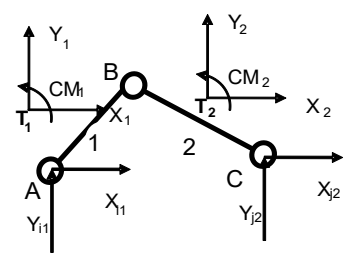

$\mathrm{b}$

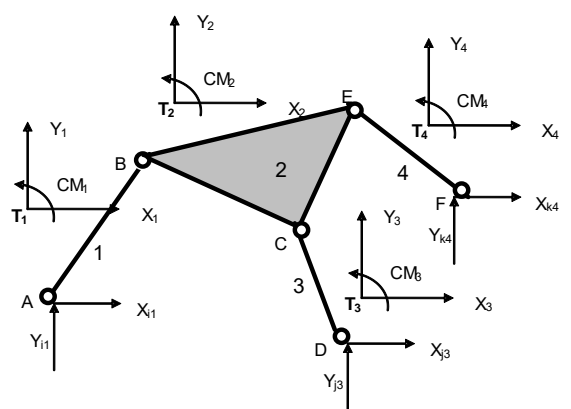

c

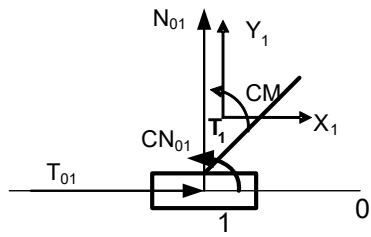

Fig. 14. The dynamic models (a) of the RRR dyad; (b) of the 6R triad; (c) of the simplest active group with a prismatic pair

For the same trajectory of the $\mathrm{T}$ point (Fig. 6) the variation for the $\mathrm{RT}_{\mathrm{k}}$ external reaction force between the contact surface and the extremity of the 6 link given is given in Fig. 15.

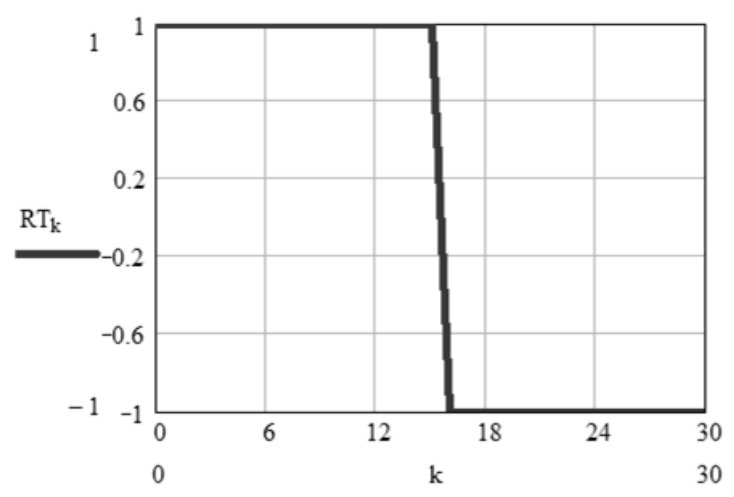

Fig. 15. The variation for the $\mathrm{RT}_{\mathrm{k}}$ external reaction force

In Fig. 16 all modular groups with their components of the reaction torque in every pair are given. 
a

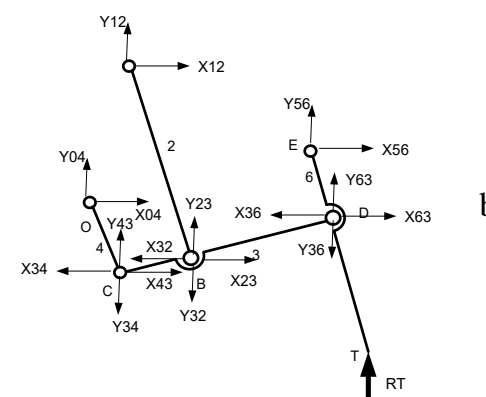

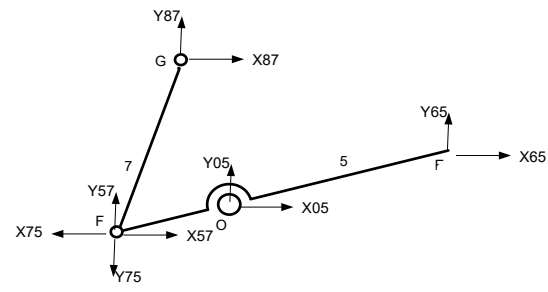

c

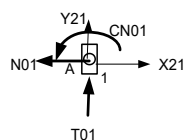

d

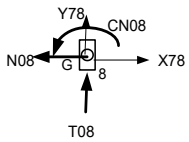

Fig. 16. The reaction torque components (a) for the $6 \mathrm{R}(2,3,4,6)$ triad; (b) for the $3 \mathrm{R}(5,7)$ dyad; (c) for the $(A, 1)$ active group; (d) for the $(G, 8)$ active group

By using the previously mentioned dynamic models [4, 5] (Fig. 14, Fig. 16) the components of the reaction torque of each pair of the bi-mobile mechanism (Fig. 1) are determined and shown in Fig. 17.
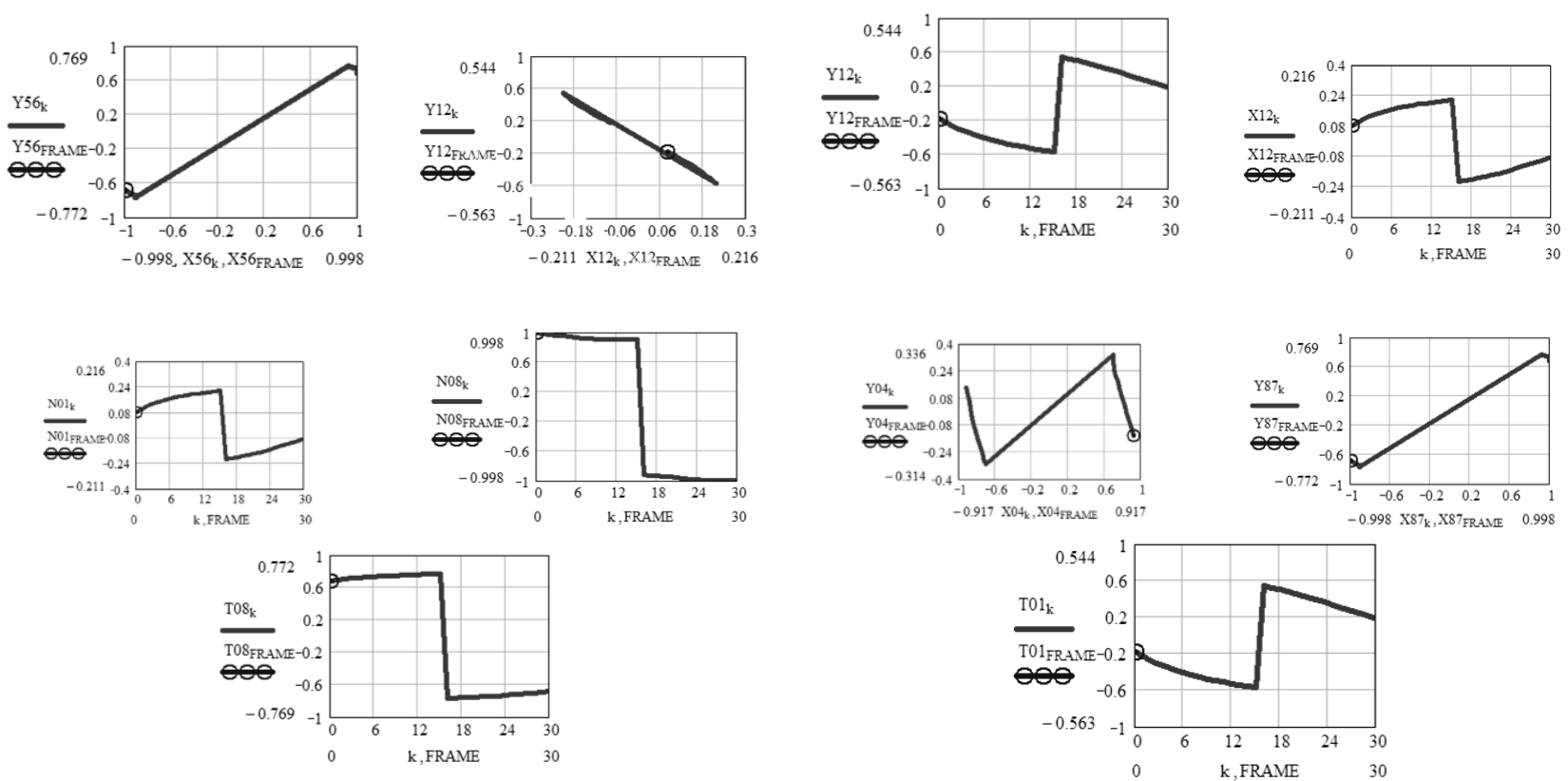

Fig. 17. The variation of the reaction torque components for pairs of the bi-mobile mechanism

\section{The structural synthesis of new bi-mobile mechanisms}

The patent of the leg mechanism previously analyzed is based on a bi-mobile linkage with three independent loops (Fig. 4). This is one of the 40 similar linkages [5, 6], which were used to find new structural solutions for such mechanisms. In the bi-mobile linkage it is necessary to establish the basis and the effector - output link, which must satisfy some conditions mentioned in the section 2 of this paper. The possible bases and effectors are given in the basis - effector matrix (Eq.1) of the bi-mobile linkage (Fig. 4). From the A[i, j] matrix any element equal to 1 may give the $i$ basis and the $\mathrm{j}$ effector, so that there are found 46 structural solutions for the bi-mobile mechanisms. In function of their inverse model characterized by an instantaneous degree of mobility equal to zero the solutions may have the following passive modular groups (PMG) connections: $2+2+2+2,2+4+2,2+2+4,4+2+2,4+4,2+6,6+2$ or 8 elements [5, 6]. All these solutions are mentioned in Table 1.

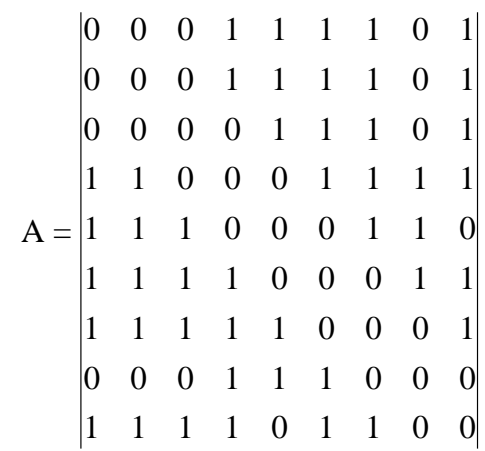




\begin{tabular}{|c|c|c|c|}
\hline $\mathrm{A}[\mathrm{i}, \mathrm{j}]$ element & Basis & Effector & Inverse model \\
\hline $\mathrm{A}[1,9]$ & 1 & 9 & PMG1 $(8,9)+$ PMG1 $(2,3)+$ PMG1 $(4,5)+$ PMG1 $(6,7)$ \\
\hline $\mathrm{A}[9,1]$ & 9 & 1 & PMG1 $(1,8)+\operatorname{PMG} 1(2,3)+\operatorname{PMG} 1(4,5)+\operatorname{PMG} 1(6,7)$ \\
\hline $\mathrm{A}[2,4]$ & 2 & 4 & PMG1 $(3,4)+$ PMG1 $(1,8)+\operatorname{PMG} 1(5,9)+\operatorname{PMG} 1(6,7)$ \\
\hline $\mathrm{A}[4,2]$ & 4 & 2 & PMG1 $(2,3)+$ PMG1 $(1,8)+$ PMG1 $(5,9)+$ PMG1 $(6,7)$ \\
\hline $\mathrm{A}[3,5]$ & 3 & 5 & PMG1 $(4,5)+\operatorname{PMG} 1(8,9)+\operatorname{PMG} 1(1,2)+\operatorname{PMG}(6,7)$ \\
\hline $\mathrm{A}[5,3]$ & 5 & 3 & PMG1 $(3,4)+$ PMG1 $(8,9)+\operatorname{PMG} 1(1,2)+\operatorname{PMG} 1(6,7)$ \\
\hline $\mathrm{A}[3,9]$ & 3 & 9 & PMG1 $(8,9)+\operatorname{PMG} 1(4,5)+\operatorname{PMG} 1(1,2)+\operatorname{PMG} 1(6,7)$ \\
\hline $\mathrm{A}[9,3]$ & 9 & 3 & PMG1 $(3,8)+\operatorname{PMG} 1(4,5)+\operatorname{PMG} 1(1,2)+\operatorname{PMG} 1(6,7)$ \\
\hline $\mathrm{A}[4,8]$ & 4 & 8 & PMG1 $(3,8)+\operatorname{PMG} 1(5,9)+\operatorname{PMG} 1(1,2)+\operatorname{PMG} 1(6,7)$ \\
\hline $\mathrm{A}[8,4]$ & 8 & 4 & PMG1 $(3,4)+$ PMG1 $(5,9)+\operatorname{PMG} 1(1,2)+$ PMG1 $(6,7)$ \\
\hline $\mathrm{A}[4,9]$ & 4 & 9 & PMG1 $(5,9)+\operatorname{PMG} 1(3,8)+\operatorname{PMG} 1(1,2)+$ PMG1 $(6,7)$ \\
\hline $\mathrm{A}[9,4]$ & 9 & 4 & PMG1 $(4,5)+\operatorname{PMG} 1(3,8)+\operatorname{PMG} 1(1,2)+\operatorname{PMG} 1(6,7)$ \\
\hline $\mathrm{A}[5,7]$ & 5 & 7 & PMG1 $(6,7)+$ PMG1 $(8,9)+\operatorname{PMG} 1(3,4)+\operatorname{PMG} 1(1,2)$ \\
\hline $\mathrm{A}[7,5]$ & 7 & 5 & PMG1 $(5,6)+$ PMG1 $(8,9)+\operatorname{PMG} 1(3,4)+\operatorname{PMG} 1(1,2)$ \\
\hline $\mathrm{A}[5,8]$ & 5 & 8 & PMG1 $(8,9)+\operatorname{PMG} 1(7,6)+\operatorname{PMG} 1(3,4)+\operatorname{PMG} 1(1,2)$ \\
\hline $\mathrm{A}[8,5]$ & 8 & 5 & PMG1 $(5,9)+$ PMG1 $(7,6)+\operatorname{PMG} 1(3,4)+\operatorname{PMG} 1(1,2)$ \\
\hline $\mathrm{A}[6,8]$ & 6 & 8 & PMG1 $(7,8)+$ PMG1 $(5,9)+\operatorname{PMG} 1(3,4)+\operatorname{PMG} 1(1,2)$ \\
\hline $\mathrm{A}[8,6]$ & 8 & 6 & PMG1 $(7,6)+$ PMG1 $(5,9)+\operatorname{PMG} 1(3,4)+$ PMG1 $(1,2)$ \\
\hline $\mathrm{A}[6,9]$ & 6 & 9 & PMG1 $(5,9)+\operatorname{PMG} 1(7,8)+\operatorname{PMG} 1(3,4)+\operatorname{PMG} 1(1,2)$ \\
\hline $\mathrm{A}[9,6]$ & 9 & 6 & PMG1 $(5,6)+$ PMG1 $(7,8)+\operatorname{PMG} 1(3,4)+$ PMG1 $(1,2)$ \\
\hline $\mathrm{A}[7,9]$ & 7 & 9 & PMG1 $(8,9)+\operatorname{PMG} 1(5,6)+\operatorname{PMG} 1(3,4)+\operatorname{PMG} 1(1,2)$ \\
\hline $\mathrm{A}[9,7]$ & 9 & 7 & PMG1 $(7,8)+\operatorname{PMG} 1(5,6)+\operatorname{PMG} 1(3,4)+\operatorname{PMG} 1(1,2)$ \\
\hline $\mathrm{A}[1,7]$ & 1 & 7 & PMG1 $(7,8)+$ PMG1 $(3,2)+$ PMG2 $(4,5,6,9)$ \\
\hline $\mathrm{A}[7,1]$ & 7 & 1 & PMG1 $(1,8)+\operatorname{PMG} 1(3,2)+\operatorname{PMG} 2(4,5,6,9)$ \\
\hline $\mathrm{A}[3,7]$ & 3 & 7 & $\operatorname{PMG} 1(7,8)+\operatorname{PMG} 1(1,2)+\operatorname{PMG} 2(4,5,6,9)$ \\
\hline $\mathrm{A}[7,3]$ & 7 & 3 & PMG1 $(3,8)+\operatorname{PMG} 1(1,2)+\operatorname{PMG} 2(4,5,6,9)$ \\
\hline $\mathrm{A}[4,1]$ & 4 & 1 & PMG3 $(1,2,3,8)+$ PMG1 $(5,9)+$ PMG1 $(6,7)$ \\
\hline $\mathrm{A}[9,2]$ & 9 & 2 & PMG3 $(1,2,3,8)+$ PMG1 $(5,6)+$ PMG1 $(1,2)$ \\
\hline $\mathrm{A}[4,6]$ & 4 & 6 & PMG1 $(5,6)+$ PMG2 $(3,7,8,9)+$ PMG1 $(1,2)$ \\
\hline $\mathrm{A}[6,4]$ & 6 & 4 & PMG1 $(4,5)+$ PMG $2(3,7,8,9)+\operatorname{PMG} 1(1,2)$ \\
\hline $\mathrm{A}[2,7]$ & 2 & 7 & PMG2 $(1,3,7,8)+$ PMG2 $(4,5,6,9)$ \\
\hline $\mathrm{A}[7,2]$ & 7 & 2 & PMG3 $(1,2,3,8)+$ PMG2 $(4,5,6,9)$ \\
\hline $\mathrm{A}[1,5]$ & 1 & 5 & PMG9(2,3,4,5,8,9)+ PMG1(6,7) \\
\hline $\mathrm{A}[5,1]$ & 5 & 1 & PMG5(1,2,3,4,8,9)+ PMG1 $(6,7)$ \\
\hline $\mathrm{A}[5,2]$ & 5 & 2 & PMG6(1,2,3,4,8,9)+ PMG1 $(6,7)$ \\
\hline $\mathrm{A}[2,5]$ & 2 & 5 & PMG8(1,3,4,5,8,9)+ PMG1 $(6,7)$ \\
\hline $\mathrm{A}[3,6]$ & 3 & 6 & PMG8 $(4,5,6,7,8,9)+\operatorname{PMG} 1(1,2)$ \\
\hline $\mathrm{A}[6,3]$ & 6 & 3 & PMG8 $(3,4,5,7,8,9)+\operatorname{PMG} 1(1,2)$ \\
\hline $\mathrm{A}[4,7]$ & 4 & 7 & PMG8 $(3,5,6,7,8,9)+\operatorname{PMG} 1(1,2)$ \\
\hline $\mathrm{A}[7,4]$ & 7 & 4 & PMG $8(3,4,5,6,8,9)+\operatorname{PMG} 1(1,2)$ \\
\hline & & & BT $23 \rightarrow$ Baranov truss \\
\hline $\mathrm{A}[1,6]$ & 1 & 6 & $2 \quad 5$ \\
\hline
\end{tabular}




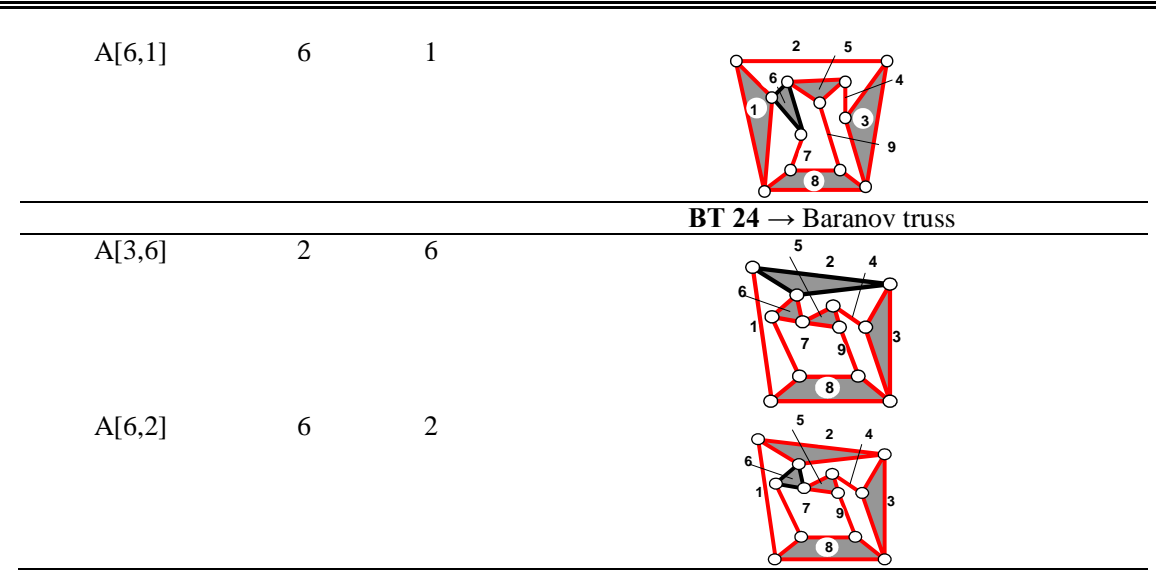

Table 1. Passive modular groups connections for $\mathrm{A}[\mathrm{i}, \mathrm{j}]=1$ solutions

\section{Conclusion}

The kinematic and dynamic analysis of a bi-mobile mechanism has some particularities. The method presented in this paper is applied when the mechanism is used to describe any curve with its effector extreme point in a technological process. In this situation in which the mechanism has two degrees of mobility the kinematic characteristics are determined by means of its structural inverse model. The direct model is applied to express its dynamic characteristics. In all situations when the mechanism has only one degree of mobility the kinematic and dynamic analysis also included in the paper involves classical aspects. Any bi-mobile planar mechanism may be analysed in a similar manner.

In the last part of the paper the author demonstrates the structural synthesis method, which allows creating new solutions for bi-mobile mechanisms. On the basis of the bi-mobile linkage with three independent loops adopted for the mechanism selected from the literature and analysed in the paper and as well as the structural solutions developed in Table 1, one may create new mechanisms similar to that included in the patent.

\section{References}

[1] M. Wang, M. Ceccarelli, Topology Search of 3 DOF Translational Parallel Manipulators with Three Identical Limbs for Leg Mechanisms, Chinese Journal of Mech.Eng., July 2015, Volume 28, Issue 4, 2015.

[2] M. Plecnik, J.M. McCarthy, Design of Stephenson Linkages that guide a point along a specified trajectory, preprint submitted to Mechanism and Machine Theory, April 27, 2015.

[3] N. Rojas, F. Thomas, Application of distance geometry to tracing coupler curves of pin-jointed linkages, Journal of Mechanisms and Robotics, vol.5, May 2013.

[4] T. Kakudou, K. Watanabe, I. Nagai, Study on Mobile Mechanism of a Climbing Robot for Stair Cleaning: a Translational Locomotion Mechanism and Turning Motion, Journal Artificial Life and Robotics, vol.17, issue 3-4, Springer-Verlag New York, 2013.

[5] Adr. Comanescu, D. Comanescu, I.Dugaesescu, Bazele modelării mecanismelor, Editura Politehnica Press, Bucureşti, (Bases of Mechanisms Modeling, Politehnica Publishing Press, Bucharest), 2010.

[6] Adr. Comanescu, D. Comanescu, I. Dugaesescu, L. Ungureanu, G. Alionte, Passive modular groups for inverse structural modelling of bi-mobile systems, Proc. of the 25th DAAAM International Symposium on Intelligent Manufacturing and Automation, 2014, Procedia Engineering, Elsevier, vol.100-2015, ISSN 1877-7058, pp.918927, 2014. 